RESEARCH ARTICLE

\title{
Genuinely Constitutive Rules
}

\author{
Bartosz Kaluziński*
}

Received: 19 November 2018 / Accepted: 28 January 2019

Abstract: In this article I am going to argue that despite the fact that (1) there is nothing specific to the form of constitutive rules and (2) that in some broad sense every rule has a constitutive aspect, there is a substantial difference between what might be called trivially and genuinely constitutive rules, and the difference can be spotted by looking at practices that rules are supposed to constitute, not at these rules.

Keywords: Constitutive rules; deep conventions; regulative rules; rules of efficiency.

\section{Introduction}

It was John Searle $(1969,1995,2005)$ who popularized the notion of constitutive rules. The basic intuition that lies behind that kind of rules is best expressed by the following slogan: if there were no rules, there would be no practice. If there were no rules of chess (football, rugby, etc.), there would be no chess (football, rugby, etc.) matches. For a long time that intuition has been accompanied by a claim that constitutive rules have

* Adam Mickiewicz University in Poznań

(iD) https://orcid.org/0000-0001-5796-4925

- Institute of Philosophy, Faculty of Social Sciences, Adam Mickiewicz University in Poznań Szamarzewskiego 89c, 60-568 Poznań, Poland

$\bowtie$ bartosz.kaluzinski@amu.edu.pl

(C) The Author. Journal compilation (C) The Editorial Board, Organon F.

This article is distributed under the terms of the Creative Commons Attribution-NonCommercial 4.0 International Public License (CC BY-NC 4.0). 
a specific form: $X$ counts as $Y$ in $C .{ }^{1}$ These rules were usually opposed to regulative rules, which govern our behaviour and say what we must/should (not) do (e.g. if you are going to the opera, wear a tie). Importantly, the activities governed by regulative rules are possible to execute without any rules - it is simply possible to wear a tie even when there are no rules in regard to what should be worn on certain specific occasions.

But there are some controversies if that picture is all right. It has been argued that rules creating new forms of practices can be reduced to rules that are regulative. Suppose that we have only rules of the form Searle attributed to constitutive rules, this is " $X$ counts as $Y$ in $C$ " (note that these rules are akin definitions that introduce new terms for types of actions/objects). The rule "such and such piece of wood counts as bishop" is basically useless without being accompanied by a set of rules that determine which moves within the game of chess are allowed, forbidden and necessary, and these rules have rather the form that was attributed to regulative rules (e.g. "In $C$, do $X$ !"). If it is the case, constitutive rules are indeed reducible to regulative ones and their function is, at best, practical/mnemonic (Hindriks and Guala 2014; Guala and Hindriks 2015). According to Hindriks, constitutive rules provide us with labels of statuses established by regulative rules: "there is an underlying reality that constitutive rules serve to make apparent" (Hindriks 2009, 237).

Moreover, it has been noted (Giddens 1984) that all rules are in some sense constitutive. Even the rules of etiquette, that Searle claimed to be a paradigm example of regulative rules, are somehow constitutive. Why is that so? Because these rules are naturally in accord with basic intuition lying behind the very distinction between constitutive and regulative rules; we can justifiably claim that "if there were no rules (of etiquette), there would be no practice (of social etiquette)." If these arguments are correct, then it appears that there are indeed no constitutive rules that are substantially different from regulative ones. As Hindriks and Guala claim:

The distinction between regulative and constitutive rules obscures the fact that both etiquette and chess are institutional

$1 X$ stands for some natural phenomena (e.g. throwing the ball into the basket) and $Y$ gives institutional description of $X$ (e.g. scoring points), $C$ stands for circumstances. 
phenomena. A better appreciation of the relation between regulative and constitutive rules makes clear that they are cogwheels of the same social machine, even though they display different grammatical forms. (Hindriks and Guala 2014, 18)

But that conclusion, I suppose, would be far-fetched. In my brief article, I am going to argue that even if it is the case that rules of the form " $X$ counts as $Y$ in $C$ " do not "create" practices or institutions by themselves, there is still a possibility to distinguish between a genuinely constitutive set of rules and a trivially constitutive set of rules, when we consider the background such rules operate within.

\section{Layers of rule-constituted practices}

Rules of the form " $X$ counts as $Y$ in $C$ " do not make certain natural actions possible. These rules are quasi-definitions of institutional terms (e.g. offside, knock-down, castling etc.), and it is obvious that physical activities (standing in a certain place at a football pitch, punching someone so hard that they fall down, moving certain wooden pieces, etc.) that $X$-terms are supposed to denote can be performed without any rules. Hindriks and Guala even claimed that:

all that constitutive rules do in comparison to regulative rules is to introduce labels or names (such as 'money' or 'property') for the statuses that figure in those regulative rules. (Hindriks and Guala 2014, 19)

Indeed it appears that constitutive rules of the form " $X$ count as $Y$ in $C$ " do not create certain activities, but they give us some names/labels that we can use when describing certain institutional activities (cf. Ruben 1997).

Arguments made by Hindriks (2009), Hindriks and Guala (2014), Guala and Hindriks (2015), and Giddens (1984) may seem good, but they miss something important. Let me start with rather an uncontroversial claim that it is not the case that there is some analogy between rules of games and constitutive rules in general, but rather if there are constitutive rules, rules of games are paradigm examples of them. So, taking a look on rules of games is probably the best way to acquire some knowledge concerning 
constitutive rules. The rulebook of chess (or any other game) contains both rules that are definitions or specifications and rules that determine which moves are allowed, necessary and forbidden within the game (for example, you cannot move the rook diagonally; the knight can be moved to a square that is two squares away horizontally and one square vertically, or two squares vertically and one square horizontally; the game is started by white). Thus, the game is constituted by the set of rules that specifies certain things (for instance, the shape of the figures) and determines what must/can (not) be done within that game.

But when proponents of the thesis that the difference between constitutive and regulative rules is a merely linguistic focus their attention on the form of rules, they miss that the practice of playing, for instance, chess, cannot be established merely by rules of that practice (Schwyzer 1969; Marmor 2007). Why is that so? What, besides rules, do we actually need to play a game? To answer those questions, let me start with a reminder of a thought experiment made by Schwyzer (1969). Suppose that you are watching two people from the other side of the globe. They do not violate rules of chess (they move pieces as they are allowed to), but their moves are rather chaotic and there is no way to spot what strategy they have adopted, why they are making these moves rather than others. After some time of this disorganized "game" there happens to be a checkmate - and now one side is deeply terrified and the other one deeply relieved. In that scenario, these people did not play chess, but they rather participated in some sort of ritual that is to determine, for example, members of which tribe will suffer from plagues sent down by gods. For it is possible that two people move wooden pieces in accordance with the rules of chess (pawns one square forward, bishops diagonally, etc.), but they do not play chess. They simply ascribe different socio-cultural sense to actions they undertake - they treat their activity as a religious ritual rather than a competitive game.

Hence, it is not sufficient to act in accordance with the rules of the practice to participate in that practice. Something that might be called "deep convention" (Marmor 2007; cf. Roversi 2014) should also be known by the participants. In case of chess, it would be a convention of playing a competitive game which, roughly speaking, may include knowledge that: 
1. Games have objectives, and the ultimate objective of a game is to win.

2. Games are "detached" from ordinary life (for instance, when a rugby player knocks down a member of the opposite team, they are not subject to criminal charges concerning assault).

3. It is possible to distinguish participants in the practice and nonparticipants, spectators (Marmor 2007).

But it is not the whole story. There are deep conventions that underpin rule-constituted practices, ${ }^{2}$ but also there is something that emerges upon the rules of the practice. One more time, let's get back to chess. There are many different types of openings, attacks and defenses - they have fancy names, ${ }^{3}$ and they specify what moves in certain circumstances should be made to achieve certain aim. Note that these rules (they might be called "rules of efficiency") are not identical to constitutive rules of chess nor are they mere paraphrases of them. In fact, it is rather the case that one can play chess without following them or even being aware of their existence. These rules are instrumental; they determine what to do within the framework of the game to eventually win the game (whereas the concept of winning is part of the deep convention of playing the competitive game). Moreover, sometimes these rules of efficiency tell us to violate some rules of the game. It is rather not possible in the case of chess, but when we play, for instance, basketball it is quite common that the losing team, when the end of the game is quite near, start to foul members of the opposite team (especially players that are bad at free throws), hoping that they will miss free throws and the losing team will have an opportunity to start their own action immediately after the miss. As Roversi noted, these rules are distinct

2 As Roversi noted, "Constitutive rules alone cannot give us genuine reasons for action unless they are embedded in a context already endowed with a social meaning: there would be no point in following the rules of chess if chess were not a game or another sort of social activity, just as it would be meaningless to realize all the formal conditions for transferring property if these conditions were not part of a legal practice" (Roversi 2014, 210).

3 There is a big Wikipedia entry that enlists them: https://en.wikipedia.org/wiki/List_of_chess_openings 
from constitutive rules but "they denote situations that can be realized only by instantiating a given game's institutional, rule-constituted elements" (Roversi 2014, 212). This is, any recommendation of as how to checkmate your opponent cannot be made before the rules concerning checkmate are in force.

It appears that, in case of such practices as games, rules that are listed in official rulebooks are not sufficient to create them. It is not possible to participate in any game without knowing the deep convention of playing a competitive game. There is another set of rules that emerge upon such practices as games: rules of efficiency. It is obviously possible to participate in a practice without knowing or adhering to these rules (probably children and, more generally, beginners and amateurs do not know these rules), but such games would be gawky and, given the ultimate objective of the practice (winning), the emergence of such rules is perfectly understandable. Hence, there is no metaphysical necessity in following these rules to participate in the practice, but normally we learn and use them because we aim at achieving the ultimate goal of the practice (in case of competitive games it is winning).

\section{Games and etiquette}

Now take a look at etiquette, which has been for a long time, treated as the best example of a practice which rules are merely regulative ones. However, it was noted that if there were no rules of etiquette there would be no social practice of etiquette, so the rules of etiquette seem to fit well into the basic intuition lying behind the very distinction of constitutive rules. But there is an important difference between games and etiquette. Namely, there are other requirements that are put on a participant of the practice. To play a game, for instance chess, you have to:

1. Know the deep convention of playing chess and intend to play.

2. Know at least at some working level, ${ }^{4}$ rules of chess.

4 This is to say, that players do not need to recite relevant passage from the rulebook. Nevertheless, it would be really odd to claim that one can play a game without any knowledge of its rules. 
But to play well, you also need to:

3. Know the rules of efficiency (and use them properly).

So, there are many things that one needs to know and intend to do to participate in a game (cf. Kaluziński 2018a). And things seem to be much different in case of etiquette. There are rules that we should eat using a fork and knife (and not with our bare hands), wear a tie when going to the opera, etc. and it looks that it is all that we need to know to participate in such a practice as social etiquette. ${ }^{5}$ Perhaps I am missing something, but it appears to me that there is no deep convention underpinning etiquette (there is nothing similar to the concept of winning that needs to be known to participate in a practice of playing chess or rugby). It is also the case that a person can participate in a practice of etiquette by merely acting in accordance with its rules (for instance, wearing a tie when going to the opera). And, lastly, there seems to be no rules of efficiency that determine how to "be good at etiquette," while there definitely are rules that tell us how to be good at chess, football and rugby. If there is any sense in speaking of "being good at etiquette," it simply consists in following its rules.

Summarizing, practices that intuitively are constituted by systems of rules (for instance, games) are indeed quite complicated. These practices are underpinned by deep conventions (in case of games, the convention of playing a competitive game). There are also rules of efficiency that provide us with the means of achieving the ultimate goal of the practice (e.g., winning). It appears that in case of such practices as etiquette, which was considered by Searle (1969) to be a practice that is not constituted by rules, things are very different and there is only one "layer of practice" — rules of etiquette.

But perhaps things are little different and there is no single "practice of social etiquette," but there are many social practices that are governed by

5 One may wonder if it is not the case that we would participate in the practice of social etiquette even in the case if we did not know its rules, because if we breach some rule of etiquette (e.g., we would try to eat soup by dinking it directly from the pot), we would face disbelief and critique from members of our society regardless of our knowledge of that rule. If it is true, the difference between participation in practice of etiquette and in such practices as games is even bigger. 
the rules of etiquette. In such a case, one may argue, it is possible to find some deep conventions (e.g. being in the boss/subordinate relationship) and my argument that we can identify/specify constitutive rules in terms of the broader practices in which those rules operate within is flawed. I have certain doubts concerning such an account. It seems analogous to the argument that there is no such thing as games and rules of games in general but only rules of specific games: chess, bridge, ice hockey, rugby etc. One may find appealing to such an account unattractive. But, for the sake of argument, let me assume that it is correct. Does it pose a grave challenge to my account? I tend to think that it does not. Of course, if one looks carefully at certain social practices, then one can spot various deep conventions. But none of them is a deep convention that underpins specifically etiquette. It might be the case that the rules of etiquette tell us how subordinates should behave towards their boss and vice versa but the very concept of business hierarchy (or chain of command) does not pertain to deep convention of etiquette but rather to the deep convention of business corporation (or military).

It appears that there is no deep convention that underpins etiquette as such but there are deep conventions that are cornerstones for various social practices or institutions like corporations or the army and our behaviour within such practices or institutions can be guided by rules of etiquette. But obviously these rules of etiquette are not realizations of deep conventions in the same sense as the rules of rugby are a realization of the deep convention of playing competitive games. Deep conventions, to use Marmor's words, are "enabling the emergence of some of the surface conventions that we normally follow" (Marmor 2007, 586) and clearly business hierarchies or chain of commands do not play that role for the rules of etiquette. Suppose that a boss in a certain enterprise is extremely polite because she wants her employees to feel valued and highly motivated, so they will work efficiently. Of course, in such circumstances the boss is following the rules of etiquette but she is doing so because the deep convention of business corporation includes the aim of maximizing profits and she believes that being polite is a good way of increasing her employees productivity. Once again, there are some deep conventions and rules of efficiency included in the reasoning that the boss makes but they do not pertain to the practice of etiquette but rather to business corporation. Note that it is not 
uncommon that in certain circumstances different deep conventions can be spotted, if we look carefully enough. For instance, when playing a professional football match, players know two deep conventions: 1) convention of playing competitive games that is necessary for their participation in that practice and 2) a convention of "chain of command" or "boss/subordinate hierarchy" that determines that they follow tactical instructions made by their team manager rather than chaotically run around the pitch. It is important not to conflate those deep conventions: only the knowledge of deep convention of playing competitive game is a necessary condition for a football match to occur, while the convention of "chain of command" is incidental for the possibility of participation in a match.

Perhaps that objection could be phrased differently. Imagine a scenario in which the deep convention is "making a workplace a more comfortable place for everyone" (without any devious intentions). This deep convention pertains to the practice of "workplace etiquette" and the rules of workplace etiquette open the space for the rules of efficiency. Clearly, there are no deep conventions that pertain to etiquette as such, but probably we could find deep conventions that pertain to workplace etiquette (and many other types of etiquette). That is interesting point but I think that such an argument is problematic. It appears that one can justifiably claim that such account is redundant because the deep convention of "making a workplace a more comfortable place for everyone" probably does not introduce new concepts (like winning in case of playing competitive games) nor it set some new requirements on participants in the practice. One can participate in the practice of workplace etiquette without any knowledge of such deep convention (whereas one cannot participate in the practice of playing rugby without knowledge of the convention of playing competitive games). Perhaps I am missing something, but it appears to me that there is no point in postulating such deep convention as "making a workplace a more comfortable place for everyone."

Lastly, one might wonder if the existence of rules of efficiency is really characteristic only for such practices as games and there is no room for such kind of rules in the case of etiquette. After all, one can use the rules of etiquette in such a way that she achieves her aims, for instance when one ignores greeting from person $\mathrm{S}$ and by doing so causes $\mathrm{S}$ to understand that 
$\mathrm{S}$ is an unwelcome guest. But even if it is the case that there are some rules that emerge on the basis of the rules of etiquette, are they the same kind of rules as rules of efficiency? I tend to think that they are not. It is crucial to remember that the deep convention that underpins rule-constituted practice can introduce new concepts and determine the ultimate aim of that practice (for instance, winning). Rules of efficiency tell us what to do in order to achieve these ultimate aims (how to win a chess match; what to do in order to win a war or scare off potential enemies, etc.) There is no similar thing in the case of etiquette, because there is no deep convention that underpins specifically etiquette. So, even if there is something like the rules of efficiency in the case of etiquette, these rules lack the feature of giving us recommendations as to how to achieve the ultimate aims of etiquette simply because there is no deep convention that specifies what the ultimate aim of etiquette is.

One might wonder if indeed there are no deep conventions that underpin certain etiquette regulated behaviour. ${ }^{6}$ But I am not sure if we can spot a deep convention that is broader and more informative than "acting appropriately," "exercising proper behaviour" or similar. Treating "exercising appropriate behaviour" as a deep convention of etiquette raises important question: if such "deep convention" is able to put similar requirements on participants in the practice of etiquette as deep convention of playing competitive game does? Going back to the thought experiment conducted by Schwyzer, one needs to ask if it is possible to participate is practice of etiquette without the knowledge of such "deep convention?" In the case of games it is clear that knowledge of deep convention is a necessary condition of playing chess or basketball, but I am sceptical if it is the case that we cannot for instance greet our colleague/boss by saying "Good morning" without the knowledge of anything more than the knowledge of the etiquette rule that tells us that we should greet our colleague/boss by saying "Good morning."

${ }_{6}$ Marmor would be reluctant to accept that claim (Marmor 2007, 606). 


\section{Genuinely and trivially constitutive rules}

Finally, I would like to introduce a distinction between genuinely constitutive rules and trivially constitutive rules. Rules of the former kind create what might be called "multi-layer practices" (for instance, games), whether rules of the latter kind create "one-layer practices" (for instance, etiquette). As it was noted in the previous sections, games are not just systems of constitutive rules, as Searle thought, but they are three-layer practices, which consist of deep convention, the system of rules, and rules of efficiency. It appears that social practice of etiquette is indeed in some very broad sense constituted by rules, but these rules are not underpinned by deep conventions and there are no rules of efficiency built upon rules of etiquette. So, we can uphold the claim that in a broad sense all rules might have a constitutive aspect, and it is right to say that "if there were no rules of etiquette, there would be no practice of etiquette." Probably, it is possible to justifiably claim something like that about virtually any rule-involving practice. But I am convinced that we are not doomed to the claim that all rules are constitutive in the exact same (and blatantly trivial) sense. Some rules are trivially constitutive and some are genuinely constitutive. The whole point is not to look at rules (because indeed there is nothing special about the form of the rules of either kind) but to look at the things that are supposed to be constituted by rules, i.e., practices or institutions. What is really important is what the effect of the existence of a certain set of rules is, not what form these rules have. And that effect could be multi-layer or one-layer practice.

It appears to me that, when discussing constitutive rules, too much attention has been paid to the form of constitutive rules, and too little to the things they are supposed to constitute. Analogically, it is like in the case when we tried to investigate what the means of production are by focusing on their physical features (e.g., that such and such machine is made of steel) and fail to notice if it can actually produce anything (and if it is able to produce something more than noise when working).

Lastly, one may wonder if the considerations presented above can be extrapolated from games to other practices. Take, for example, such practice as the legislative process. It appears that there is some deep convention 
lying behind it; namely, concepts of authority or representation are needed (for instance, we should know that members of parliament act not as private persons but as legitimate representatives of the society; one that does not have concepts of authority or representation would be clueless when watching a broadcast of parliamentary debates). Then there is a "proper" set of rules (enlisted in constitution and some other legal acts) that determine how new laws are passed: who can be a member of parliament (e.g., age census), how MPs are elected (electoral law), and how decisions in the parliament are to be made (e.g., by majority of votes in the presence of at least half the number of members of parliament and then the bill should be signed by the president). And finally, there is a set of rules of efficiency that tell us how to use powers and duties introduced by these "proper" rules to achieve ultimate goal of a practice (passing the bill smoothly or blocking the bill by using, for instance, filibuster). Hence, at the first glance, the analysis provided in this brief paper is not limited to such practices as games.

There is one important clarification I should make at this point. I claim that genuinely constitutive rules take part in creating multi-layer practices and one may wonder if it is not the case that we can make any rules genuinely constitutive ones by just supplementing trivially constitutive rules (for instance rules of etiquette) with two additional layers, e.g. by (A) a rule that everybody should strive to be better at etiquette than everybody else and (B) creating rules on how to effectively achieve this. When I say that genuinely constitutive rules take part in the creation of multi-layer practice I mean that there is a "cascade" of layers. First, we have deep convention that underpins a practice (for instance, the convention of playing a competitive game). Without the knowledge of deep convention there is no possibility to participate in the relevant practice. Second, there is a system of constitutive rules (the rulebook of chess, rugby, football, etc.). Rules of this kind are just different forms of the realization of the very general idea of competitive games. Third, there are rules of efficiency that tell us how to achieve our aims (and, most importantly, the ultimate aim of the practice) within the frame of the practice that is made by the system of rules. Hence, one cannot turn rules of etiquette into genuinely constitutive rules just by adding arbitrarily two kinds of rules because these rules do not meet the criteria deep conventions and rules of efficiency need to meet: they are not 
necessary for the very possibility of participation in a practice; rules of etiquette do not seem to be a form of realization of (A) like the rules of basketball are a form of realization of the deep convention of playing competitive games; since there is no ultimate aim of the practice of etiquette there are no rules of efficiency that recommend to us certain moves that may help us achieve that aim.

Even if it is the case that traditionally understood constitutive rules (as having the form " $X$ count as $Y$ in $C$ ") are reducible to rules that have form attributed to regulative rules, there is still a possibility to differentiate genuinely constitutive rules from trivially constitutive ones. We just need to not look at the form of the rules, but rather at the reality that they are supposed to "create." If that part of reality is a simple, one-layer practice, then rules that "constitute" that practice are constitutive only in a broad and trivial sense. We can indeed say that "if there were no rules, there would be no practice." However, this can probably be said about all ruleinvolving practices. But there are also rules that are part of multi-layer practices or institutions. These rules are genuinely and non-trivially constitutive. Why? Because they take part in creation of complicated practices that pose other requirements for participants in these practices. To participate in an etiquette-like practice, it is sufficient that a person follows (or not) its rules or, perhaps, it is even the case that she can participate in it without awareness of these rules. But to participate in, for instance, a game of chess one needs to know relevant deep convention, intend to play and being committed to following (at least some subset of) its rules. Normally, one also needs to know and properly use rules of efficiency to have a shot at winning (achieving the ultimate goal of the practice of playing a game).

Summarising, even if Guala and Hindriks (2015) or Giddens (1984) are right to claim that rules that traditionally have been called "constitutive" are reducible to regulative rules, and, then, even paradigm example of regulative rules appears to fit into the slogan "if there were no rules, there would be no practice," it is not the case that we cannot distinguish genuinely and trivially constitutive rules. Genuinely constitutive rules are part of multi-layer practices. To spot them, we need to look not at rules, but rather at practices that these rules are supposed to constitute. If we look carefully enough, we can spot if there is a deep convention underpinning 
the practice, and if there are rules of efficiency built upon these rules. That might be hard, but it is necessary to spot non-trivially constitutive rules. Hence, when Guala and Hindriks say that "constitutive rules are, at roots, just regulative rules dressed up in institutional language" (Guala and Hindriks 2015, 189), they are mistaken if their claim is to be understood as applied to the function of rules. Perhaps the slogan that expresses the basic intuition lying behind the notion of genuinely constitutive rules should be "If there were no rules and deep conventions (plus, normally, rules of efficiency), then would be no practice."

\section{Conclusions}

In the most orthodox account of constitutive rules they are characterized by their form and opposed to regulative rules, but there are also alternative views that emphasize that constitutive rules have a strong normative aspect of determining what should (not) or may be done within the practice (cf. Ransdell 1973; Hindriks 2009; Hindriks and Guala 2014; Guala and Hindriks 2015; Kaluziński 2018b). These accounts face a challenge: they need to provide some new characterization of constitutive rules that do not blur the distinction of constitutive rules from other types of rules. Most notable accounts of Hindriks (2009), Hindriks and Guala (2014), Guala and Hindriks (2015) steer in the direction of "constitutive rules reductionism:" they claim that constitutive rules are reducible to regulative ones and their sole function is to provide us with labels that are referring to statuses established by regulative rules. Their role is purely practical/mnemonic. In this paper I tried to show that this is not the only viable option. I argue that there is another way to specify constitutive rules in terms of the broader practices in which those rules are applied. If we take deep conventions and rules of efficiency into account, we can identify genuinely constitutive rules even if we emphasize the normative side of these rules.

\section{Funding}

The work on this paper was funded by National Science Center, Poland, grant under award number 2015/19/D/HS1/00968. 


\section{Acknowledgements}

I would like to thank two anonymous reviewers of this journal whose insightful comments helped me improve my paper.

\section{References}

Giddens, Anthony. 1984. The Constitution of Society. Berkeley: University of California Press.

Guala, Francesco, and Hindriks, Frank. 2015. "A Unified Social Ontology." The Philosophical Quarterly 65 (259): 178-201. https://doi.org/10.1093/pq/pqu072

Hindriks, Frank. 2009. "Constitutive Rules, Language, and Ontology." Erkenntnis 71 (2): 253-75. https://doi.org/10.1007/s10670-009-9178-6

Hindriks, Frank, and Guala, Francesco. (2014), "Institutions, Rules, and Equilibria: A Unified Theory." Journal of Institutional Economics 11 (3): 459-80. https://doi.org/10.1017/S1744137414000496

Kaluziński, Bartosz. 2018a. "What Does It Mean that Constitutive Rules Are in Force?" Argumenta 4 (1): 111-12. https://doi.org/10.14275/2465-2334/20187.kal

Kaluziński, Bartosz. 2018b. "Rules and Games." Philosophia. https://doi.org/10.1007/s11406-018-0050-2

Marmor, Andrei. 2007. "Deep Conventions." Philosophy and Phenomenological Research 74 (3): 586-610. https://doi.org/10.1111/j.1933-1592.2007.00041.x

Ransdell, Joseph. 1971. "Constitutive Rules and Speech-Act Analysis." Journal of Philosophy 68 (13): 385-99. https://doi.org/10.2307/2025037

Roversi, Corrado. 2014. "Conceptualizing Institutions." Phenomenology and the Cognitive Sciences 13 (1): 201-15. https://doi.org/10.1007/s11097-013-9326-y

Ruben, David-Hillel. 1997. "John Searle's The Construction of Social Reality." Philosophy and Phenomenological Research 57 (2): 443-47. https://doi.org/10.2307/2953734

Schwyzer, Hubert. 1969. "Rules and Practices." The Philosophical Review 78 (4): 451-67. https://doi.org/10.2307/2184198

Searle, John. 1969. Speech Acts: An Essay in the Philosophy of Language. Oxford: Oxford. https://doi.org/10.1017/CBO9781139173438

Searle, John. 1995. The Construction of Social Reality. New York: The Free Press. Searle, John. 2005. "What Is an Institution?" Journal of Institutional Economics, 1 (1): 1-22. https://doi.org/10.1017/S1744137405000020 